Proceedings of the 33rd Annual Scientific Meeting of the European Embryo Transfer Association (AETE); Bath, United Kingdom, September 8th and 9th, 2017.

\title{
Follicular environment and oocyte maturation: roles of local peptides and steroids
}

\author{
José Buratini' ${ }^{1}$, Ana Caroline Silva Soares, Rodrigo Garcia Barros \\ Department of Physiology, Institute of Biosciences, São Paulo State University, Botucatu, SP, Brazil.
}

\begin{abstract}
A large amount of data on the mechanisms regulating cumulus-oocyte maturation in mammals has been generated in the last 20 years. It has been made clear that oocyte-secreted factors play a central role in the control of cumulus differentiation and oocyte developmental competence. However, more recent data indicate that cumulus-derived factors are also involved. In this mini-review, we have compiled and discussed data produced in our laboratory about the involvement of oocyte and cumulus-derived peptides, including fibroblast growth factors, bone morphogenetic protein 15, Kit ligand and natriuretic peptide $C$, in the regulation of cumulus metabolism and oocyte nuclear maturation. In addition, we discuss the interaction of follicular steroids with natriuretic peptide $\mathrm{C}$ in the control of meiosis progression.
\end{abstract}

Keywords: oocyte, cumulus cells, intrafollicular peptides, steroids, in vitro maturation, cattle.

\section{Introduction}

There is great interest to improve efficiency of in vitro maturation of oocytes (IVM) in animal species and humans as IVM has been considered the main technological bottleneck to improve embryo in vitro production following in vitro fertilization (IVF). It has been clearly demonstrated that current IVM systems do not adequately reproduce the follicular environment where the cumulus-oocyte complex (COC) physiologically differentiates, which compromises cumulus cells function and oocyte developmental competence (Rizos et al., 2002; Brown et al., 2017). Therefore, understanding the mechanisms that regulate COC differentiation is critical for the improvement of IVM systems.

The bidirectional interaction between the oocyte and cumulus cells is essential for oocyte developmental competence and constitutes a valuable parameter for improving IVM/IVF outcomes (Gilchrist, 2011). A lot of attention has been given to secreted paracrine factors as mediators of the oocyte-cumulus communication, mainly to oocyte secreted factors (OSF). There is robust evidence that OSF, particularly bone morphogenetic protein 15 (BMP15) and growth differentiation factor 9 (GDF9), both members of the transforming growth factor- $\beta$ (TGF- $\beta$ ) superfamily, and fibroblast growth factors (FGF) regulate various aspects of cumulus cells differentiation such as expansion, metabolism, steroidogenesis and apoptosis (Eppig, 2001; Sugiura et al., 2007; Gilchrist et al., 2008;
Caixeta et al., 2013b). However, data obtained in cattle and pigs suggest that the importance of OSF in the control of cumulus expansion and metabolism may vary between species (Buccione et al., 1990; Vanderhyden, 1993; Ralph et al., 1995; Sutton et al., 2003; Caixeta et al., 2013b). Although the other direction of the oocytecumulus communication has been less explored, there is recent evidence that cumulus derived peptides regulate nuclear maturation and gene expression in the oocyte (Lima et al., 2016).

Apart from secreted factors, oocyte-cumulus communication is also mediated by transzonal cytoplasmic projections (TZP), which are extensions of cumulus cells that cross the zona pellucida transporting ions, metabolites and regulatory molecules (Albertini et al., 2001). The delivery of glucose metabolites and small regulatory molecules through gap junctions connecting the end of the TZPs with the ooplasm appears crucial for the control of meiosis, chromatin configuration, transcriptional activity and metabolism of the oocyte (Conti et al., 2012; Luciano et al., 2014; Gilchrist et al., 2016; Brown et al., 2017). In addition to the transport through gap junctions, recent studies indicate that TZPs can also deliver larger molecules such as RNA transcripts via micro-vesicles in a transport mechanism designated as the gametic synapse (Macaulay et al., 2014). In fact, cumulus-derived RNA has been identified in oocyte polyribosomes suggesting that the gametic synapse can influence the translational activity of the oocyte (Macaulay et al., 2016).

This paper aims to review and discuss some of the recent data on paracrine mediators of the oocytecumulus interaction, as well as mechanisms regulating periovulatory differentiation of cumulus cells and oocyte nuclear maturation with potential practical implications for IVM.

\section{Oocyte vs. cumulus secreted factors: who runs the show in the cow?}

A large body of data produced in mice points to a leading role for the oocyte in the regulation of cumulus cells differentiation and metabolism (Matzuk et al., 2002; Gilchrist et al., 2008). However, studies using microsurgical removal of the oocyte from the COC and co-culture of oocytectomized COCs with secreting denuded oocytes indicate that OSF are needed for cumulus expansion in mice, but not in cattle, pigs or rats (Buccione et al., 1990; Ralph et al., 1995; Vanderhyden et al., 2003). More recently, the same approach demonstrated that OSF also play a central role in the regulation of glycolytic activity of cumulus cells in mice (Sugiura et al., 2005), whereas in cattle, utilization 
of oxygen, glucose, pyruvate and lactate by cumulus cells was not affected by removal of the oocyte (Sutton et al., 2003). Taken together, these data point to differences between species with regard to the participation of the oocyte in cumulus differentiation, raising speculation that autocrine and paracrine signaling within the cumulus may be more influential in species other than the mouse. In mono-ovulatory mammals, the functional relevance of intra-cumulus TGF- $B$ signaling is controversial. Studies assessing the expression patterns of BMP15 and GDF9 in the COC are conflicting. While expression of BMP15 and GDF9 has been consistently detected in the oocyte, in cumulus cells it was observed in one but not all studies in cattle (Hosoe et al., 2011; Crawford and McNatty, 2012).

Alternatively, FGF2 and Kit Ligand (KL) are two potential and less controversial cumulus-derived regulators of COC maturation. A microarray study pointed FGF2 as an important up-regulated gene in the predicted pathways activated by the LH surge to induce final differentiation of bovine cumulus cells (Assidi et al., 2010). In addition, we have shown that transcription of FGFR2C and FGFR3C, two receptors efficiently activated by FGF2, is drastically and rapidly increased in cumulus cells from bovine COCs subjected to FSHstimulated IVM, suggesting that sensitivity to FGF2 is enhanced with activation of the ovulatory cascade (Zhang et al., 2006; Caixeta et al., 2013a). Taken together, these studies indicate that FGF2 signaling is enhanced in preparation for ovulation and final COC maturation. In fact, recent data from our laboratory suggest the involvement of FGF2 in the regulation of meiosis progression, cumulus expansion and apoptosis (Buratini J.; 2017; Institute of Biosciences, São Paulo State University, Botucatu, SP, Brazil; unpublished data). Moreover, the involvement of FGF2 in the control of COC maturation is also consistent with our previous finding that FGF2 increases phosphorylation of extracellular signal-regulated kinase $1 / 2($ ERK1/2) and phosphoinositide-3-kinase/v-akt murine thymoma viral oncogene homolog (PI3K/AKT) in granulosa cells, two pathways known to regulate meiotic resumption and cumulus expansion (Jiang et al., 2011; Prochazka et al., 2012).

On the other hand, we have recently reported that mRNA levels of KL increase around 10 times in bovine cumulus cells during FSH-stimulated IVM and presented evidence of a role for KL in the regulation of meiosis progression under the influence of OSF in cattle (Lima et al., 2016). These data are compiled and discussed in further details below. Therefore, whilst further studies are needed to address the importance of cumulus derived peptides for COC maturation, the data collected so far suggest that OSF are less influential in the cow than in the mouse and that an interaction of oocyte and cumulus derived factors likely runs the show in the cow.

\section{Oocyte secreted factors in the control of cumulus expansion and metabolism}

Although OSF are not absolutely required for cumulus expansion in cattle, they appear to influence this process (Ralph et al., 1995; Zhang et al., 2010a; Caixeta et al., 2013b). BMP15 and FGF10 are expressed by the oocyte and when added to the IVM medium they can enhance cumulus expansion and embryo production in cattle (Hussein et al., 2006; Buratini et al., 2007; Zhang et al., 2010a; Crawford and McNatty, 2012). We have provided evidence that BMP15 and FGF10 control the expression of key genes in the ovulatory cascade. Supplementation of the IVM medium with BMP15 increased transcription of disintegrin and metalloprotease 10 (ADAM 10), ADAM 17, amphiregulin (AREG) and epiregulin (EREG) in cumulus cells from bovine COCs. Alternatively, treatment with FGF10 promptly increased mRNA levels of prostaglandin (PG)-endoperoxide synthase (PTGS2), and subsequently of pentraxin 3 (PTX3) and tumor necrosis factor alpha-induced protein 6 (TNFAIP6) in bovine cumulus cells (Caixeta et al., 2013b). Therefore, BMP15 appears to enhance the ovulatory cascade right at its beginning by increasing production, cleavage and release of EGF-like factors, the last two events being a consequence of ADAM10 and ADAM17 activity (reviewed by Ben-Ami et al., 2006). These effects of BMP15 are consistent with its positive impact on developmental competence in cattle (Hussein et al., 2006) and with evidences of suboptimal EGF signaling in bovine COCs matured in vitro (Brown et al., 2017). On the other hand, FGF10 would act downstream of EGF-like factors by increasing the expression of crosslinking proteins that stabilize the extracellular matrix (PTX3 and TNFAIP6). This appears to be at least in part mediated by the preceding prompt increase in PTGS2 expression, since PGE2 is required for TNFAIP6 expression (Ochsner et al., 2003, reviewed by Russell and Robker, 2007). These findings are in agreement with the positive effect of FGF10 on embryo production following IVM/IVF and with higher expression of TNFAIP6 in cumulus cells from in vivo matured compared with in vitro matured bovine COCs (Tesfaye et al., 2009; Zhang et al., 2010a).

Despite the evidences that BMP15 and FGF10 act at different steps of the ovulatory cascade, they appear to act similarly with regard to their influence on glucose metabolism. They both increased glucose uptake without altering lactate production during IVM of bovine COCs, which was accompanied by increases in mRNA levels of glucose transporters (GLUT1 and GLUT4). Interestingly, BMP15 and FGF10 also increased mRNA abundance of glucosamine:fructose-6$\mathrm{PO}_{4}$ transaminases (GFPT1 and GFPT2) and hyaluronan synthase 2 (HAS2), which are rate-limiting enzymes in the hexosamine pathway of glucose metabolism that leads to the production of hyaluronic acid, the major component of the extracellular matrix (Sutton-McDowall et al., 2010; Caixeta et al., 2013b). Therefore, collectively, these data suggest that after the activation of the ovulatory cascade BMP15 and FGF10 direct the metabolism of glucose towards the synthesis of hyaluronic acid to support the formation of extracellular matrix for cumulus expansion.

Nevertheless, at earlier stages of COC maturation, before the activation of the ovulatory 
cascade, the influence of BMP15 and FGFs on glucose metabolism may be different. BMP15 and FGF8 were shown to cooperate to increase the expression and activity of glycolytic enzymes phosphofructokinase (PFKP) and lactate dehydrogenase (LDHA) in cumulus cells from COCs arrested at the germinal vesicle $(\mathrm{GV})$ stage in mice (Sugiura et al., 2007). On the other hand, in bovine COCs undergoing IVM, the combination of BMP15 with FGF17, a member of the FGF8 superfamily also expressed by the bovine oocyte and capable of activating the same receptors that FGF8, did not alter PFKP mRNA levels in cumulus cells (Zhang et al., 2006; Machado et al., 2009, 2015). Therefore, additional studies dissecting the influence of species, COC developmental stage and culture conditions are needed for a clearer understanding of the roles of OSF in the regulation of glucose metabolism in the COC.

Like FGF10, FGF17 was shown to enhance expansion of bovine COCs during IVM (Machado et al., 2015). However, FGF17 did not alter the expression of PTGS2, or any of the genes in the ovulatory cascade investigated [ADAM10, ADAM17, AREG, EREG, PTX3, TNFAIP6, VERS (versican) and HAS2]. Therefore, different FGFs appear to impact on cumulus expansion and differentiation through different mechanisms. Although no additional effect on cumulus expansion or meiosis progression was observed when FGF17 was combined with BMP15 during IVM, this combination increased mRNA levels of the nuclear progesterone receptor (nPR) in cumulus cells after IVM, as well as the number of cells in the inner cell mass (ICM) of blastocysts produced by IVF/IVC (Machado et $a l ., 2015)$. These data therefore suggest that FGFs and BMP15 interact during COC maturation to improve developmental competence, which may be at least in part a consequence of increased progesterone sensitivity. Previous studies using inhibitors of progesterone synthesis and nPR antagonists have elegantly demonstrated that progesterone signaling is crucial for cumulus expansion and oocyte developmental competence (Aparicio et al., 2011).

\section{Oocyte and cumulus-derived factors in the regulation of nuclear maturation and cumulus- oocyte communication}

A major and well recognized limitation of IVM is the asynchrony between oocyte nuclear and cytoplasmic maturation. Chromatin condensation is precipitated and transcriptional activity diminishes abruptly when the COC is removed from the follicle (Hyttel et al., 1987; Lodde et al., 2007). Therefore, preIVM cultures containing agents capable of delaying nuclear maturation such as natriuretic peptide precursor $\mathrm{C}$ (NPPC) and phosphodiesterase inhibitors have been proposed to improve the outcomes of IVM/IVF in cattle (Albuz et al., 2010; Franciosi et al., 2014), although these strategies have not yet provided consistent results in different breeds and laboratories (Gilchrist et al., 2015).

Robust studies using Nppc and Npr2 (natriuretic peptide receptor B) mutant mice first demonstrated the importance of NPPC signaling for meiotic arrest. A model has been proposed and widely accepted in which NPPC produced predominantly by mural granulosa cells activates natriuretic peptide receptor B (NPR2) on cumulus cells to induce production of cGMP, which is then transferred to the oocyte through gap junctions, deviating the activity of phosphodiesterase 3 from cAMP. This would maintain cAMP at levels required to prevent the synthesis of maturation promoting factor (MPF), thus holding the oocyte in meiotic arrest (Zhang et al., 2010b; Conti et al., 2012). Later studies demonstrated that NPPC is expressed by bovine cumulus cells, and that, like in the mouse, NPPC also inhibits germinal vesicle breakdown (GVBD) in cattle (Franciosi et al., 2014; De Cesaro et al., 2015). For meiosis resumption to occur, LH inhibits NPPC production by granulosa cells and reduces the flow of cGMP from the outer layers of the cumulus to the oocyte (Kawamura et al., 2011; Shuhaibar et al., 2015). Reduced gap junction functionality after the LH surge is believed to be a consequence of the production/secretion of EGF-like peptides that bind to the EGFR to induce mitogen activated protein kinase (MAPK) dependent phosphorylation of connexins, the main components of gap junctions (Conti et al., 2012).

Therefore the influence of NPPC on nuclear maturation depends on the functionality of gap junctions between cumulus cells and the oocyte. The importance of gap junction mediated communication for meiotic arrest and developmental competence was unequivocally demonstrated by studies where chemically induced gap junction uncoupling led to chromatin condensation and decreased transcriptional activity in the bovine oocyte (Luciano et al., 2011). And since these effects were neutralized by co-treatment with cilostamide, an oocyte specific phosphodiesterase inhibitor, it was concluded that the impact of gap junction functionality is mediated by intra-oocyte cAMP. This is in agreement with a later study from the same group reporting positive effects of NPPC and cilostamide on gap junction functionality in cattle (Franciosi et al., 2014).

Interestingly, the influence of NPPC appears to be regulated by intrafollicular steroids. In mice, estradiol is required to maintain the ability of NPPC to stimulate cGMP production and to prevent GVBD in culture, and both estradiol and testosterone can increase mRNA levels of Npr2 in cumulus cells (Zhang et al., 2011). The enhancement of NPPC action by steroids also occurs in cattle. We have recently demonstrated that intrafollicular steroids cooperate with NPPC to slow nuclear maturation and to increase gap junction mediated cumulus-oocyte communication in the bovine COC. More specifically, co-treatment with estradiol, progesterone and adrostenedione at physiological concentrations enhanced the ability of NPPC to inhibit GVBD and to increase the transfer of a dye from the oocyte to cumulus cells, which was accompanied by an increase in NPR2 mRNA levels. Therefore, the enhanced effects on nuclear maturation and gap junction functionality were interpreted as a consequence of greater NPPC signaling and cGMP production in the 
presence of steroids. Moreover, the combination of NPPC with follicular steroids in a pre-IVM culture promoted improved embryo quality (assessed by total cell number), suggesting that this strategy may be useful to improve IVM/IVF outcomes (Soares et al., 2017).

The NPPC system is also regulated by cumulus and oocyte-derived factors. We have recently reported evidence of a link between NPPC and KL under the influence of OSF in cattle. In mammals, Kit ligand is expressed by granulosa cells since very early stages of folliculogenesis and activates the receptor KIT on the oocyte and theca cells (Hutt et al., 2006; Thomas and Vanderhyden, 2006). The roles of KL signaling in periovulatory COC differentiation have not been deeply investigated and are controversial; KL delayed 1st polar body extrusion in rats (Ismail et al., 1997), but did the opposite in mice (Ye et al., 2009). In cattle, first we demonstrated that mRNA levels of both isoforms of KL, $\mathrm{KL} 1$ and KL2, increase during the first $12 \mathrm{~h}$ of FSHstimulated IVM in cumulus cells, suggesting that KL transcription is enhanced in preparation for ovulation. Secondly, we observed that KL supplementation during IVM of bovine COCs does not affect cumulus expansion, but enhances oocyte maturation as assessed by the percentage of oocytes reaching metaphase II. To investigate the mechanisms by which KL impacts on nuclear maturation, we assessed its effects on the expression of genes regulating meiosis in the bovine COC. Kit ligand did not alter mRNA levels of NPR2, but decreased mRNA abundance of NPPC in bovine cumulus cells. In addition, KL increased expression of Y-box binding protein 2 (YBX2) in the oocyte, a protein that regulates RNA stability and protein synthesis and is required for normal spindle formation (Medvedev et al., 2011). Finally, we assessed whether the oocyte regulates $\mathrm{KL}$ expression in cumulus cells using the oocytectomy model, and observed mRNA levels around 5 times more abundant in oocytectomized compared with intact COCs at the end of IVM. The increase in KL expression was completely abrogated by co-culture with denuded oocytes, indicating that the influence of the oocyte on KL expression is mediated by OSF. Conversely and in agreement with the inhibitory influence of KL on NPPC expression described above, oocytectomy markedly decreased mRNA levels of NPPC in cumulus cells. The specific OSF that mediate the effects of KL on cumulus NPPC expression appear to vary between species and remain to be completely identified. In our studies, treatment with FGF10 during IVM decreased KL2 mRNA expression, suggesting that FGF10 may be one of these OSF in cattle (Lima et al., 2016). Taken together, these data suggest that the oocyte and cumulus derived factors interact to control meiosis. It is tempting to speculate that an increase in cumulus KL expression overcoming the inhibitory effect of the oocyte through NPPC signaling may be part of the mechanisms leading to meiosis resumption in the periovulatory period in cattle.

\section{Concluding remarks}

In this mini-review we compile data indicating that oocyte and cumulus derived factors interact to regulate cumulus differentiation, nuclear maturation and oocyte developmental competence in cattle. In addition, we present published evidence that steroids modulate the influence of cumulus-derived factors on meiosis progression and cumulus-oocyte communication. The data compiled herein widens our view of the mechanisms that regulate meiosis and cumulus function in cattle, and represent useful parameters for the improvement of IVM/IVF outcomes.

\section{References}

Albertini DF, Combelles CM, Benecchi E, Carabatsos MJ. 2001. Cellular basis for paracrine regulation of ovarian follicle development. Reproduction, 121:647-653.

Albuz FK, Sasseville M, Lane M, Armstrong DT, Thompson JG, Gilchrist RB. 2010. Simulated physiological oocyte maturation (SPOM): a novel in vitro maturation system that substantially improves embryo yield and pregnancy outcomes. Hum Reprod, 25:2999-3011.

Aparicio IM, Garcia-Herreros M, O'Shea LC, Hensey C, Lonergan P, Fair T. 2011. Expression, regulation, and function of progesterone receptors in bovine cumulus oocyte complexes during in vitro maturation. Biol Reprod, 84:910-921.

Assidi M, Dieleman SJ, Sirard MA. 2010. Cumulus cell gene expression following the LH surge in bovine preovulatory follicles: potential early markers of oocyte competence. Reproduction, 140:835-852.

Ben-Ami I, Freimann S, Armon L, Dantes A, Ron-El R, Amsterdam A. 2006. Novel function of ovarian growth factors: combined studies by DNA microarray, biochemical and physiological approaches. Mol Hum Reprod, 12:413-419.

Brown HM, Dunning KR, Sutton-McDowall M, Gilchrist RB, Thompson JG, Russell DL. 2017. Failure to launch: aberrant cumulus gene expression during oocyte in vitro maturation. Reproduction, 153:R109-R120.

Buccione R, Vanderhyden BC, Caron PJ, Eppig JJ. 1990. FSH-induced expansion of the mouse cumulus oophorus in vitro is dependent upon a specific factor(s) secreted by the oocyte. Dev Biol, 138:16-25.

Buratini J, Pinto MG, Castilho AC, Amorim RL, Giometti IC, Portela VM, Nicola ES, Price CA. 2007. Expression and function of fibroblast growth factor 10 and its receptor, fibroblast growth factor receptor $2 \mathrm{~B}$, in bovine follicles. Biol Reprod, 77:743-750.

Caixeta ES, Machado MF, Ripamonte P, Price C, Buratini J. 2013a. Effects of FSH on the expression of receptors for oocyte-secreted factors and members of the EGF-like family during in vitro maturation in cattle. Reprod Fertil Dev, 25:890-899.

Caixeta ES, Sutton-McDowall ML, Gilchrist RB, Thompson JG, Price CA, Machado MF, Lima PF, Buratini J. 2013b. Bone morphogenetic protein 15 and fibroblast growth factor 10 enhance cumulus expansion, glucose uptake, and expression of genes in the ovulatory cascade during in vitro maturation of bovine cumulus- 
oocyte complexes. Reproduction, 146:27-35.

Conti M, Hsieh M, Zamah AM, Oh JS. 2012. Novel signaling mechanisms in the ovary during oocyte maturation and ovulation. Mol Cell Endocrinol, 356:6573.

Crawford JL, McNatty KP. 2012. The ratio of growth differentiation factor 9: bone morphogenetic protein 15 mRNA expression is tightly co-regulated and differs between species over a wide range of ovulation rates. Mol Cell Endocrinol, 348:339-343.

De Cesaro MP, Macedo MP, Santos JT, Rosa PR, Ludke CA, Rissi VB, Gasperin BG, Gonçalves PB 2015. Natriuretic peptides stimulate oocyte meiotic resumption in bovine. Anim Reprod Sci, 159:52-59.

Eppig JJ. 2001. Oocyte control of ovarian follicular development and function in mammals. Reproduction, 122:829-838.

Franciosi F, Coticchio G, Lodde V, Tessaro I, Modina SC, Fadini R, Dal Canto M, Renzini MM, Albertini DF. Luciano AM. 2014. Natriuretic peptide precursor $\mathrm{C}$ delays meiotic resumption and sustains gap junction-mediated communication in bovine cumulusenclosed oocytes. Biol Reprod. 91:61. doi: 10.1095/biolreprod.114.118869.

Gilchrist RB, Lane M, Thompson JG. 2008. Oocytesecreted factors: regulators of cumulus cell function and oocyte quality. Hum Reprod Update, 14:159-177.

Gilchrist RB. 2011. Recent insights into oocyte-follicle cell interactions provide opportunities for the development of new approaches to in vitro maturation. Reprod Fertil Dev, 23:23-31.

Gilchrist RB, Zeng HT, Wang X, Richani D, Smitz J, Thompson JG. 2015. Reevaluation and evolution of the simulated physiological oocyte maturation system. Theriogenology, 84:656-657.

Gilchrist RB, Luciano AM, Richani D, Zeng HT, Wang X, Vos MD, Sugimura S, Smitz J, Richard FJ, Thompson JG. 2016. Oocyte m.aturation and quality: role of cyclic nucleotides. Reproduction, 152:R143-157. Hosoe M, Kaneyama K, Ushizawa K, Hayashi KG, Takahashi T. 2011. Quantitative analysis of bone morphogenetic protein 15 (BMP15) and growth differentiation factor 9 (GDF9) gene expression in calf and adult bovine ovaries. Reprod Biol Endocrinol, 9:33. doi: 10.1186/1477-7827-9-33.

Hussein TS, Thompson JG, Gilchrist RB. 2006 Oocyte-secreted factors enhance oocyte developmental competence. Dev Biol, 296:514-521.

Hutt KJ, McLaughlin EA, Holland MK. 2006. Kit ligand and c-Kit have diverse roles during mammalian oogenesis and folliculogenesis. Mol Hum Reprod, 12:61-69.

Hyttel P, Xu KP, Smith S, Callesen H, Greve T. 1987. Ultrastructure of the final nuclear maturation of bovine oocytes in vitro. Anat Embryol (Berl), 176:35-40.

Ismail RS, Dubé M, Vanderhyden BC. 1997. Hormonally regulated expression and alternative splicing of kit ligand may regulate kit-induced inhibition of meiosis in rat oocytes. Dev Biol, 184:333342 .

Jiang ZL, Ripamonte P, Buratini J, Portela VM, Price CA. 2011. Fibroblast growth factor-2 regulation of Sprouty and NR4A genes in bovine ovarian granulosa cells. J Cell Physiol, 226:1820-1827.

Kawamura K, Cheng Y, Kawamura N, Takae S, Okada A, Kawagoe Y, Mulders S, Terada Y, Hsueh AJ. 2011. Pre-ovulatory LH/hCG surge decreases Ctype natriuretic peptide secretion by ovarian granulosa cells to promote meiotic resumption of pre-ovulatory oocytes. Hum Reprod, 26:3094-3101.

Lima PF, Ormond CM, Caixeta E, Barros RG, Price C, Buratini J. 2016. Effect of kit ligand on natriuretic peptide precursor $\mathrm{C}$ and oocyte maturation in cattle. Reproduction, 152:481-489.

Lodde V, Modina S, Galbusera C, Franciosi F, Luciano AM. 2007. Large-scale chromatin remodeling in germinal vesicle bovine oocytes: interplay with gap junction functionality and developmental competence. Mol Reprod Dev, 74:740-749.

Luciano AM, Franciosi F, Modina SC, Lodde V. 2011. Gap junction-mediated communications regulate chromatin remodeling during bovine oocyte growth and differentiation through cAMP-dependent mechanism(s). Biol Reprod, 85:1252-1259.

Luciano AM, Franciosi F, Dieci C, Lodde V. 2014. Changes in large-scale chromatin structure and function during oogenesis: a journey in company with follicular cells. Anim Reprod Sci, 149:3-10.

Macaulay AD, Gilbert I, Caballero J, Barreto R, Fournier E, Tossou P, Sirard MA, Clarke HJ, Khandjian É, Richard FJ, Hyttel P, Robert C. 2014. The gametic synapse: RNA transfer to the bovine oocyte. Biol Reprod, 91:90. doi: 10.1095/biolreprod.114.119867.

Macaulay AD, Gilbert I, Scantland S, Fournier E, Ashkar F, Bastien A, Saadi HA, Gagné D, Sirard MA, Khandjian É, Richard FJ, Hyttel P, Robert C. 2016. Cumulus cell transcripts transit to the bovine oocyte in preparation for maturation. Biol Reprod, 94:16. doi: 10.1095/biolreprod.114.127571.

Machado MF, Portela VM, Price CA, Costa IB, Ripamonte P, Amorim RL, Buratini J. 2009. Regulation and action of fibroblast growth factor 17 in bovine follicles. J Endocrinol, 202:347-353.

Machado MF, Caixeta ES, Sudiman J, Gilchrist RB, Thompson JG, Lima PF, Price CA, Buratini J. 2015. Fibroblast growth factor 17 and bone morphogenetic protein 15 enhance cumulus expansion and improve quality of in vitro-produced embryos in cattle. Theriogenology, 84:390-398.

Matzuk MM, Burns KH, Viveiros MM, Eppig JJ. 2002. Intercellular communication in the mammalian ovary: oocytes carry the conversation. Science, 296:2178-2180

Medvedev S, Pan H, Schultz RM. 2011. Absence of MSY2 in mouse oocytes perturbs oocyte growth and maturation, RNA stability, and the transcriptome. Biol Reprod, 85:575-583.

Ochsner SA, Russell DL, Day AJ, Breyer RM, Richards JS. 2003. Decreased expression of tumor necrosis factor-alpha-stimulated gene 6 in cumulus cells of the cyclooxygenase-2 and EP2 null mice. Endocrinology, 144:1008-1019.

Prochazka R, Blaha M, Nemcova L. 2012. Signaling 
pathways regulating FSH- and amphiregulin-induced meiotic resumption and cumulus cell expansion in the pig. Reproduction, 144:535-546.

Ralph JH, Telfer EE, Wilmut I. 1995. Bovine cumulus cell expansion does not depend on the presence of an oocyte secreted factor. Mol Reprod Dev, 42:248253.

Rizos D, Ward F, Duffy P, Boland MP, Lonergan P. 2002. Consequences of bovine oocyte maturation, fertilization or early embryo development in vitro versus in vivo: implications for blastocyst yield and blastocyst quality. Mol Reprod Dev, 61:234-248.

Russell DL, Robker RL. 2007. Molecular mechanisms of ovulation: co-ordination through the cumulus complex. Hum Reprod Update, 13:289-312.

Shuhaibar LC, Egbert JR, Norris RP, Lampe PD, Nikolaev VO, Thunemann M, Wen L, Feil R, Jaffe LA. 2015. Intercellular signaling via cyclic GMP diffusion through gap junctions restarts meiosis in mouse ovarian follicles. Proc Natl Acad Sci USA, 112:5527-5532.

Soares AC, Lodde V, Barros RG, Price CA, Luciano AM, Buratini J. 2017. Steroid hormones interact with natriuretic peptide $\mathrm{C}$ to delay nuclear maturation, to maintain oocyte-cumulus communication and to improve the quality of in vitro-produced embryos in cattle. Reprod Fertil Dev. doi: 10.1071/RD16320.

Sugiura K, Pendola FL, Eppig JJ. 2005. Oocyte control of metabolic cooperativity between oocytes and companion granulosa cells: energy metabolism. Dev Biol, 279:20-30.

Sugiura K, Su YQ, Diaz FJ, Pangas SA, Sharma S, Wigglesworth K, O'Brien MJ, Matzuk MM, Shimasaki S, Eppig JJ. 2007. Oocyte-derived BMP15 and FGFs cooperate to promote glycolysis in cumulus cells. Development, 134:2593-2603.

Sutton ML, Cetica PD, Beconi MT, Kind KL, Gilchrist RB, Thompson JG. 2003. Influence of oocyte-secreted factors and culture duration on the metabolic activity of bovine cumulus cell complexes. Reproduction, 126:27-34.

Sutton-McDowall ML, Gilchrist RB, Thompson JG. 2010. The pivotal role of glucose metabolism in determining oocyte developmental competence. Reproduction, 139:685-695.

Tesfaye D, Ghanem N, Carter F, Fair T, Sirard MA, Hoelker M, Schellander K, Lonergan P. 2009. Gene expression profile of cumulus cells derived from cumulus-oocyte complexes matured either in vivo or in vitro. Reprod Fertil Dev, 21:451-461.

Thomas FH, Vanderhyden BC. 2006. Oocytegranulosa cell interactions during mouse follicular development: regulation of kit ligand expression and its role in oocyte growth. Reprod Biol Endocrinol, 4:19. doi: 10.1186/1477-7827-4-19.

Vanderhyden BC. 1993. Species differences in the regulation of cumulus expansion by an oocyte-secreted factor(s). J Reprod Fertil, 98:219-227.

Vanderhyden BC, Macdonald EA, Nagyova E, Dhawan A. 2003. Evaluation of members of the TGFbeta superfamily as candidates for the oocyte factors that control mouse cumulus expansion and steroidogenesis. Reprod Suppl. 61:55-70.

Ye Y, Kawamura K, Sasaki M, Kawamura N, Groenen P, Gelpke MD, Rauch R, Hsueh AJ, Tanaka T. 2009. Kit ligand promotes first polar body extrusion of mouse preovulatory oocytes. Reprod Biol Endocrinol, 7:26. doi: 10.1186/1477-7827-7-26.

Zhang K, Hansen PJ, Ealy AD. 2010a. Fibroblast growth factor 10 enhances bovine oocyte maturation and developmental competence in vitro. Reproduction, 140:815-826.

Zhang M, Su YQ, Sugiura K, Xia G, Eppig JJ. 2010b. Granulosa cell ligand NPPC and its receptor NPR2 maintain meiotic arrest in mouse oocytes. Science, 330:366-369.

Zhang M, Su YQ, Sugiura K, Wigglesworth K, Xia G, Eppig JJ. 2011. Estradiol promotes and maintains cumulus cell expression of natriuretic peptide receptor 2 (NPR2) and meiotic arrest in mouse oocytes in vitro. Endocrinology, 152:4377-4385.

Zhang X, Ibrahimi OA, Olsen SK, Umemori H, Mohammadi M, Ornitz DM. 2006. Receptor specificity of the fibroblast growth factor family. The complete mammalian FGF family. J Biol Chem 281 15694-15700. 